\title{
The prospective study on prevalence of menstrual disorders in school going adolescents at Sangareddy district, Telangana
}

\author{
Priyanka Rajipet, Ajith Kumar Vemula*, Praveena Rathod, \\ Kavya Valmeekam, Sandhya Rani Rakuditti
}

Department of Pharmacy Practice, MNRCOP, Sangareddy District, Telangana, India

Received: 06 April 2021

Accepted: 04 May 2021

\section{*Correspondence:}

Dr. Ajith Kumar Vemula,

E-mail: ajithkumaraj415@gmail.com

Copyright: (C) the author(s), publisher and licensee Medip Academy. This is an open-access article distributed under the terms of the Creative Commons Attribution Non-Commercial License, which permits unrestricted non-commercial use, distribution, and reproduction in any medium, provided the original work is properly cited.

\begin{abstract}
Background: Menstrual disorders are common sources of morbidity among adolescent girls. Overall, $75 \%$ of adolescent's experience problems with menstruation either with delaying in onset, irregular menstrual cycles, painful or heavy periods. The study was aimed to evaluate the prevalence and examine the key areas of need and explore the experience of adolescent girls with menstrual problems like dysmenorrhea, Amenorrhea, menorrhagia and PMS.

Methods: The study employed prospective observational design. The pre-designed, self-administered, semi-structured questionnaire was used to elicit the data from 1100 adolescents selected from Government schools in and around Sangareddy district, Telangana by random sampling technique. Data was analyzed by using Chi-square test in Statistical package for social sciences (SPSS) version 22.

Results: A total of $(65.6 \%)$ subjects were unaware of menstruation before menarche. The mean age at menarche was found to be $12.5 \pm 1.36$ years. Dysmenorrhea $(\mathrm{N}=158.6)$ and PMS $(\mathrm{N}=125.7)$ were most commonly reported disorders. Majority of subjects have complained about abdominal pain $(\mathrm{N}=719)$. Many of subjects $(\mathrm{N}=292.7)$ were found to have history of menorrhagia. Many of them reported about irregular periods $(\mathrm{N}=172)$. Study resulted there is positive correlation between dysmenorrhea and dysmenorrhea with PMS with $\mathrm{p}$ value $<0.05$ and also amenorrhea and amenorrhea with dysmenorrhea with $\mathrm{p}$ value $<0.05$ which are significant.

Conclusions: This study revealed that majority of girls prone to menstrual problems which often goes unreported due to lack of knowledge on their reproductive health. Hence there is a huge need of educating and screening programs in schools for early diagnosis and management of menstrual disorders, which will improve quality of life and also lower the risks for future diseases.
\end{abstract}

Keywords: Menstruation, Menstrual disorders, Adolescent girls, Prevalence, Abdominal pain, Screening programs

\section{INTRODUCTION}

Adolescence is the transitional phase of physical and psychological changes between childhood and adulthood, it is characterized by immense hormonal changes. ${ }^{1,2}$ According to $\mathrm{WHO}$, adolescent range in the age group of $10-19$, the most striking change in adolescent girls is the onset of menstruation, i.e. menarche; generally occurs approximately 2-3 years after the initiation of puberty between ages of 11-14 years in $95 \%$ girls depending on race, ethnicity, socioeconomics and nutritional status. ${ }^{3-6}$ Menstruation is the normal physiological phenomenon in a girl indicating her capability for procuation. ${ }^{7}$ It is generally considered as an unclean in Indian society especially and restrictions being imposed on them may result in negative attitude towards this phenomenon. ${ }^{8}$ In many areas of developing countries, a culture of silence surrounds the topic of menstruation and related issues. ${ }^{9}$ Prior to menarche, it is an important biological milestone 
in a women's life as it makes the onset of reproductive phase of her life. ${ }^{10-12}$ Awareness of menstruation before menarche helps the adolescent girls to prepare physically, psychologically and emotionally. Lack of awareness may cause serious underlying problems in future..$^{10,13}$

Overall, $75 \%$ of adolescent experience menstruation associated problems like dysmenorrhea, PMS and menstrual irregularities like amenorrhea, and menorrhagia. ${ }^{14,15}$ Menstrual cycles often are irregular through adolescence, particular the interval from first cycle to second cycle. Becoming less frequent as they grow older 3-5 years after menarche. Thus, menstruation in adolescent is different from adult women. ${ }^{1}$ Menstrual irregularities can be caused by disturbances of central gonadotropin-releasing hormone plus generation as well as by significant weight loss, strenuous exercise, substantial change in sleeping or eating habits and severe stressors. Due to environmental factors, including socio-economic conditions, nutrition, there is lot of variation in timing and progression of puberty, so what was considered normal for adolescent menstrual cycle previously may not be normal in current scenario. ${ }^{1}$

Dysmenorrhea is the most common gynecologic complaint among adolescent with prevalence ranging from 50-80\% worldwide. ${ }^{10,14}$ Pain begins shortly before or at onset of menstrual flow and last about 2-3 days and their discomfort range from mild to severe. ${ }^{16,17}$

The absence of menstruation is characterized as amenorrhea, the primary amenorrhea is a failure to menstruate by the age 16 years in the presence of normal growth and secondary sexual characteristics, secondary amenorrhea refers to cessation of menstruation for six consecutive months in female who have attained menarche. ${ }^{13,18}$

Menorrhagia denotes excessive menstrual bleeding of greater than $80 \mathrm{ml} /$ cycle or menstrual flow lasting $>7$ days. $^{7,19}$ The prevalence of objectively measurable menorrhagia has been considered to be around $10 \% 20$ and the most common cause is dysfunctional uterine bleeding related to anovulation. ${ }^{15}$

PMS is cyclic constellation of symptoms occurring in second half of menstrual cycle, the symptoms occur a week to 10 days between the start of menstrual blood loss. ${ }^{1,21}$ Survey have estimated that the frequency of PMS is quite high i.e., $80-90 \% .^{22}$ The symptoms include bloating, gain in weight, myalgia, backache, headache, tiredness, lethargy, fatigue, breast tenderness, depressive mood, irritability and decrease in concentration. .,6,23 $^{1}$

Menstrual problems not only carry an economic burden but also one of the most common cause of absenteeism and poor academic performance. ${ }^{24}$ Measures should be taken to educate the adolescent and their mothers about menstrual disorders and to mitigate their effects on social and academic lives of the adolescents. ${ }^{10}$ Poor hygienic practices and inadequate self-care are major determinant of morbidity and other complications like RTI's and UTI's. ${ }^{9,25}$

The aim and objective of the study is to identify the prevalence and examine the key areas of need and explore the experience of adolescent girls with menstrual problems like dysmenorrhea, Amenorrhea, menorrhagia and PMS.

\section{METHODS}

The prospective observational study was conducted among adolescent school going girls of government schools in and around Sangareddy district, Telangana. The survey was conducted from November 2019 to December 2020. Firstly, permission to carry out the study was sought from school authorities. Out of 10 Govt schools present in the field practice area, 8 were selected by simple random sampling method. From these schools, 6th -10th standard students were randomly selected for study. A total of 1100 , out of 1250 questionnaires administered were correctly filled out and returned (response rate 88\%). The respondents were aged between $10-16$ years. Students who didn't attained menarche and with incomplete data were excluded from the study. A pre-designed, pretested and structured questionnaire in both English and local language was prepared and used for data collection. The questions pertained to complete demographic, source of information, menstrual problems, regularities of menses, menorrhagia and dysmenorrhea in past cycles of menstruation and effect of their problem's in daily routine of subjects According to the serial numbers in attendance register girls were enrolled to avoid bias and their anonymity was maintained by keeping their details confidential throughout study and were used only for research purpose. After taking informed consent, the data was collected through self- administered questionnaire. The severity of menstrual pain was measured by visual analogue scale (VAS). After collecting data, educational sessions were conducted for girls by visualizing helpful videos regarding girl related subject by using digital technology and distributed leaflet aids which contained standardized information and important counselling points to every individual girl who participated in the study.

\section{Statiscal analysis}

At $95 \%$ confidence interval, the sample size worked out to be 1100 . Statistical analysis was done by using SPSS version 22 , to find out the prevalence of menstrual disorders and their association with demographics of respondents was conducted by using chi-square test; $\mathrm{p}$ value equal to and less than 0.05 was taken as significant.

\section{RESULTS}

The total number of girls enrolled in the study from all selected schools were 1250 . However due to incomplete entries 150 questionnaires could not be included in final analysis resulting in attrition rate of $12 \%$. 
Table 1: Prevalence of menstrual disorders by age at data collection.

\begin{tabular}{|c|c|c|c|c|}
\hline Menstrual Disorder & $\begin{array}{l}\text { Age group (10-13) } \\
\mathrm{N}\end{array}$ & $\begin{array}{l}\text { Age group (14-16) } \\
\text { N }\end{array}$ & $\mathbf{X}$ & P-value \\
\hline Dysmenorrhea & 110 & 48 & \multirow{2}{*}{12.8} & \multirow{2}{*}{$<0.05$} \\
\hline Dysmenorrhea with PMS & 94 & 92 & & \\
\hline Dysmenorrhea & 110 & 48 & \multirow{2}{*}{2.61} & \multirow{2}{*}{$>0.05$} \\
\hline Dysmenorrhea with Amenorrhea & 68 & 45 & & \\
\hline PMS & 39 & 86 & \multirow{2}{*}{11.2} & \multirow{2}{*}{$<0.05$} \\
\hline Dysmenorrhea with PMS & 94 & 92 & & \\
\hline Amenorrhea & 26 & 33 & \multirow{2}{*}{3.98} & \multirow{2}{*}{$<0.05$} \\
\hline Dysmenorrhea with Amenorrhea & 68 & 45 & & \\
\hline
\end{tabular}

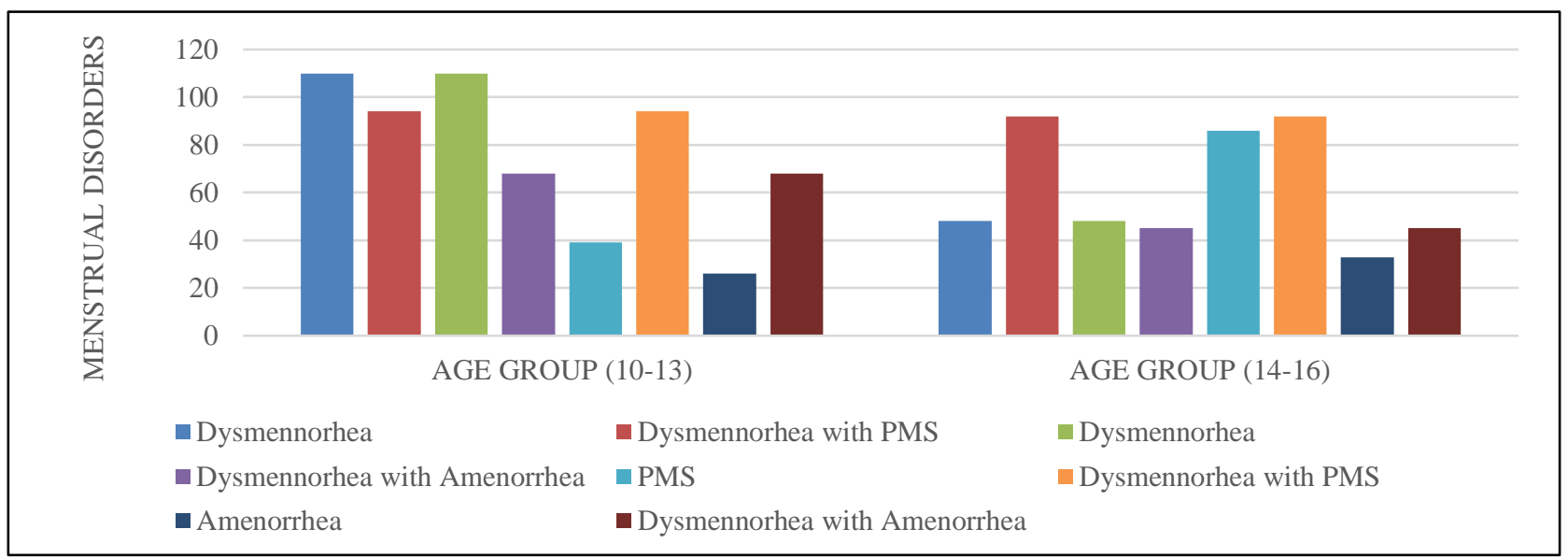

Figure 1: Menstrual disorders in accordance with age groups.

Among 1100 school going adolescent girls studied, maximum was in age group between 11-14 years. Mean age at menarche was found to be $12.5 \pm 1.36$ years. Most of their mothers were illiterate, from rural background. $65.6 \%$ of subjects did not have awareness about menstruation before menarche while $34.4 \%$ were known. The source of information was their mothers $(25 \%)$ followed by friend, sister, relative and internet. Typical menstruation consisted of regular menses in $70 \%$ of girls, a cycle length ranging from 21-35 days.

Table 2: Pre-menstrual symptoms.

\begin{tabular}{|l|l|}
\hline Symptoms & No of subjects (n) \\
\hline Abdominal Pain & 719 \\
\hline Backache & 526 \\
\hline Irritability & 490 \\
\hline Weakness & 361 \\
\hline Psychological upset & 305 \\
\hline $\begin{array}{l}\text { Generalized body } \\
\text { pains }\end{array}$ & 288 \\
\hline Headache & 209 \\
\hline Dizziness & 134 \\
\hline Nausea and Vomiting & 44 \\
\hline
\end{tabular}

From table 2, majority of girls were experiencing some type of pain. Abdominal pain $(65.3 \%)$ was more prevalent and found to be most common symptom, followed by backache $(47.8 \%)$, irritability $(44.5 \%)$, weakness $(32.8 \%)$, psychological upset $(27.72 \%)$, generalized body pains $(26.8 \%)$, headache $(19 \%)$, dizziness $(14 \%)$, nausea and vomiting $(4 \%)$ where self-care strategies are necessary.

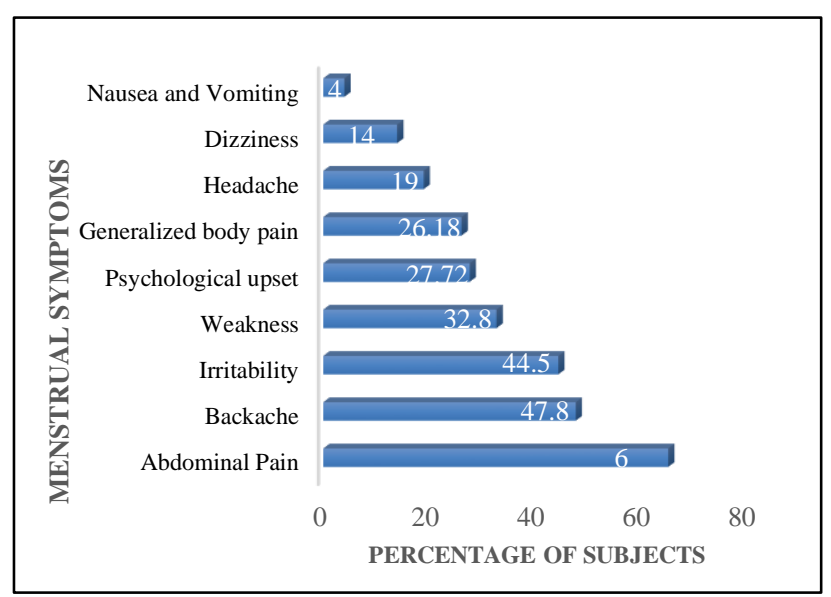

Figure 2: Pre-menstrual symptoms.

Dysmenorrhea and dysmenorrhea with other menstrual disorders were reported by about 458 subjects, majority of subjects have moderate pain $(\mathrm{N}=207)$ followed by mild $(\mathrm{N}=131)$ and severe $(\mathrm{N}=120)$. Only dysmenorrhea was reported by 158.6 subjects. It is associated with PMS and 
Amenorrhea and results were reported as $\mathrm{N}=186.3$ and $\mathrm{N}=113.04$ as shown in table 1.172 subjects of total population complained about having irregular periods (amenorrhea) with menstrual cycle lengths larger than 35 days. 292.7 subjects were reported with heavy bleeding with continuous flow of menses more than 7 days.

Table 3: Menstrual disorders.

\begin{tabular}{|lll|}
\hline Menstrual disorders & $\begin{array}{l}\text { No. of } \\
\text { subjects (n) }\end{array}$ & $\begin{array}{l}\text { Percentage } \\
(\%)\end{array}$ \\
\hline Irregular cycle & 172 & 18.4 \\
\hline $\begin{array}{l}\text { History of } \\
\text { menorrhagia }\end{array}$ & 292 & 31.2 \\
\hline Dysmenorrhea & 158 & 17 \\
\hline Amenorrhea & 59 & 6 \\
\hline PMS & 120.5 & 13 \\
\hline
\end{tabular}

From table 3, the result of menstrual disorders was reported individually as the regular cycles from total subjects were about $81.5 \%$, irregular cycles were $18.4 \%$, subjects having history of menorrhagia $31.2 \%$, dysmenorrhea $17 \%$ amenorrhea $6 \%$ and PMS $13 \%$.

\section{DISCUSSION}

Dysmenorrhea was most commonly reported by majority of students with moderate pain followed by mild and severe in accordance to Gilany et al study. ${ }^{5,24-30}$ Dysmenorrhea is also associated with other menstrual disorders. Consequently, as suggested in our study group, many girls appear to suffer needlessly from dysmenorrhea. The potential reasons are at least twofold in nature: girls believe that menstrual cramps are a normal female experience, even when accompanied with severe pain, nausea, vomiting, diarrhoea, headache, dizziness, and fatigue; and they are not aware that therapy can relieve their distress. ${ }^{28}$ Accordingly, it was suggested that importance of nutritional status of adolescent girl may reduce dysmenorrhea and to cope with dysmenorrhea adolescent use various strategies that span from medical to non-medical approaches. Prior to awareness regarding menarche and menstruation among girls is generally low in rural areas in our country i.e., $65.5 \%$ were ignorant about menstruation before menarche and $33.4 \%$ were aware of it, which is similar to the study by Bhattacharya et al. $^{8}$ In case of PMS, abdominal pain was the major contributor $(65.3 \%)$ followed by backache, irritability, weakness, psychological stress, generalized body pains, headache, dizziness and least was nausea and vomiting (4\%) similar to study done by Purva shoor. ${ }^{1,29}$ Girls use various strategies to overcome PMS like lifestyle modifications, communicating with others, seeking medical devices, selecting nutritional diet and reducing physical activity during menses to prevent aggravating of symptoms.

The study tends that menses lasted between 3-7 days of menstrual flow in $80 \%$ of cycles with average duration of 5 days, $31.2 \%$ menorrhagia observed in study was alarming as heavy menstrual flow also effects psychosocial and academic lives of adolescent and put them at risk of anemia in accordance to Dewhurst et al and other researchers also. ${ }^{9,24}$ From the study $6 \%$ of subjects were reported with absence of periods (amenorrhea) and 18.4\% are with irregular menstrual cycles. Even though menstrual disorders, the study reports $81.5 \%$ subjects have regular menstrual cycle.

Findings highlights that the information girls were receiving is insufficient to prepare them for menarche. The results reported that mother is the major source of information to adolescent girls regarding menstruation and menstrual patterns which is similar to Thakre et al study.8 Emotional maternal support must be provided at the time of menarche which is associated with positive experience of menarche. Girls reported many challenges in managing menstrual symptoms at school but some schools lack basic facilities, such as a first aid room with ready access to pain relief, heat-packs or highly absorbent sanitary products. The study finds $61.8 \%$ were reported as school absenteeism and the main reason was dysmenorrhea and others are leaking, lack of privacy, staining and smell.in similar to Bani Karim et al. ${ }^{2,30}$ Measures should be taken to educate the adolescent and their mothers about menstrual disorders and to mitigate their effects on social and academic lives of the adolescents.

\section{CONCLUSION}

Menstrual problems are frequent among adolescents which often goes unreported due to lack of knowledge on their reproductive health, so there is a need of education and screening programs for early diagnosis, management of menstrual problems, which would show a great impact on their reproductive health. Implementing awareness programs will improve academic performance and understanding selfcare strategies, life style modifications and dietary practices are needed to cope up menstrual discomforts.

Funding: No funding sources

Conflict of interest: None declared

Ethical approval: The study was approved by the Institutional Ethics Committee

\section{REFERENCES}

1. Patavegar BN, Rasheed NA, Pathak RA, Kapilashrami $\mathrm{MC}$, Farookee AB. Menstrual pattern and menstrual disorders among school going adolescent girls in Delhi. J Applied Basic Res Int. 2015;11:241-6.

2. Li AD, Bellis EK, Girling JE, Jayasinghe YL, Grover SR, Marino JL, Peate M. Unmet needs and experiences of adolescent girls with heavy menstrual bleeding and dysmenorrhea: a qualitative study. J Paediat Adolesc Gynaecol. 2020;33(3):278-84.

3. Mahanta TG, Boruah M, Singh VK, Gogoi P, Rane T, Mahanta BN. Effect of social and behaviour change communication by using infotainment in community 
perception of adolescent girls for reproductive and sexual health care in high priority districts of Assam. Clinical Epidemiology and Global Health. 2016;4(3):133-9.

4. Cakir M, Mungan I, Karakas T, Girisken I, Okten A. Menstrual pattern and common menstrual disorders among university students in Turkey. Pediat Int. 2007;49(6):938-42.

5. Abdelmoty HI, Youssef MA, Abdel-Malak K, Hashish NM, Samir D, Abdelbar M et al. Menstrual patterns and disorders among secondary school adolescents in Egypt. A cross-sectional survey. BMC women's health. 2015;15(1):1-6.

6. Vani RK, Veena KS, Subitha L, Kumar HVR, Bupathy A. Menstrual Abnormalities in School Going Girls-Are They Related to Dietary and Exercise Pattern?. J Clinic Diagnost Res. 2013;7(11):2537.

7. Lakkawar NJ, Jayavani RL, Arthi PN, Alaganandam P, Vanajakshi N. A study of menstrual disorders in medical students and its correlation with biological variables. Sch J App Med Sci. 2014;2(6E):3165-75.

8. Kapoor G, Kumar D. Menstrual hygiene: Knowledge and practice among adolescent school girls in rural settings. Int J Reprod Contracept Obstet Gynecol. 2017;6(3):959-62.

9. Haque SE, Rahman M, Itsuko K, Mutahara M, Sakisaka $\mathrm{K}$. The effect of a school-based educational intervention on menstrual health: an intervention study among adolescent girls in Bangladesh. BMJ open. 2014;4(7).

10. Amu EO, Bamidele JO. Prevalence of menstrual disorders among adolescent girls in Osogbo, South Western Nigeria. International journal of adolescent medicine and health. 2014;26(1):101-6.

11. Kaur R, Kaur K, Kaur R. Menstrual hygiene, management, and waste disposal: Practices and challenges faced by girls/women of developing countries. J Environmen Pub Heal. 2018;2018.

12. Slap GB. Menstrual disorders in adolescence. Best practice \& research Clinical obstetrics \& gynaecology. 2003;17(1):75-92.

13. Zafar M, Sadeeqa S, Latif S, Afzal H. Pattern and prevalence of menstrual disorders in adolescents. Int $\mathrm{J}$ Pharmaceutic Sci Res. 2017;2088-99.

14. Azurah AG, Sanci L, Moore E, Grover S. The quality of life of adolescents with menstrual problems. Journal of pediatric and adolescent gynecology. 2013;26(2):102-8.

15. Lee LK, Chen PC, Lee KK, Kaur J. Menstruation among adolescent girls in Malaysia: a cross-sectional school survey. Singapore medical journal. 2006;47(10):869.

16. Eryilmaz G, Ozdemir F. Evaluation of menstrual pain management approaches by Northeastern Anatolian adolescents. Pain Management Nursing. 2009;10(1):407.

17. Campbell MA, McGrath PJ. Use of medication by adolescents for the management of menstrual discomfort. Archives of pediatrics \& adolescent medicine. 1997;151(9):905-13.

18. Peacock A, Alvi NS, Mushtaq T. Period problems: disorders of menstruation in adolescents. Archives of disease in childhood. 2012;97(6):554-60.

19. Nam GE, Han K, Lee G. Association between sleep duration and menstrual cycle irregularity in Korean female adolescents. Sleep medicine. 2017;35:62-6.

20. Kadir RA, Edlund M, Von Mackensen S. The impact of menstrual disorders on quality of life in women with inherited bleeding disorders. Haemophilia. 2010;16(5):832-9.

21. Indusekhar R, O'Brien S. Psychological aspects of premenstrual syndrome. Best Practice \& Research Clinical Obstetrics \& Gynaecology. 2007;21(2):207-20.

22. Yoshimi K, Shiina M, Takeda T. Lifestyle Factors Associated with Premenstrual Syndrome: A Crosssectional Study of Japanese High School Students. Journal of pediatric and adolescent gynecology. 2019;32(6):590-5.

23. Czajkowska M, Drosdzol-Cop A, Gałązka I, Naworska B, Skrzypulec-Plinta V. Menstrual cycle and the prevalence of premenstrual syndrome/premenstrual dysphoric disorder in adolescent athletes. J Pediat Adolesce Gynecol. 2015;28(6):492-8.

24. Rafique N, Al-Sheikh MH. Prevalence of menstrual problems and their association with psychological stress in young female students studying health sciences. Saudi medical journal. 2018;39(1):67.

25. Revel-Vilk S, Paltiel O, Lipschuetz M, Ilan U, Hyam E, Shai E, Varon D, Revel A. Underdiagnosed menorrhagia in adolescents is associated with underdiagnosed anemia. J Pediat. 2012;160(3):468-72.

26. Banikarim C, Chacko MR, Kelder SH. Prevalence and impact of dysmenorrhea on Hispanic female adolescents. Arch Pediat Adolesc Med. 2000;154(12):1226-9.

27. Golub LJ, Lang WR, Menduke H. The incidence of dysmenorrhea in high school girls. Postgraduate medicine. 1958;23(1):38-40.

28. Wilson CA, Keye Jr WR. A survey of adolescent dysmenorrhea and premenstrual symptom frequency: a model program for prevention, detection and treatment. J Adolesc Heal Care. 1989;10(4):317-22.

29. Shoor P. A study of knowledge, attitude, and practices of menstrual health among adolescent school girls in urban field practice area of medical college, Tumkur. Ind J Heal Sci Biomed Res. 2017;10(3):249.

30. Bata MS. Age at menarche, menstrual patterns, and menstrual characteristics in Jordanian adolescent girls. Int J Gynecol Obstets. 2012;119(3):281-3.

Cite this article as: Rajipet $\mathrm{P}$, Vemula $\mathrm{AK}$, Rathod P, Valmeekam K, Rakuditti SR. The prospective study on prevalence of menstrual disorders in school going adolescents at Sangareddy district, Telangana. Int J Reprod Contracept Obstet Gynecol 2021;10:2443-47. 